UDC 69.001.5

Author: GRYAZNOV Igor Vasilevich, Engineer, Director of the STE Ltd. TARK; Novya, 3a, 43, Pavlograd, Dnipropetrovsk region, Ukraine, 51413, e-mail: lustann@mail.ru;

Author: FIGOVSKY Oleg Lvovich, Full Member of European Academy of Sciences, Foreign Member of REA and RAASN, Editor-in-Chief of Journals SITA (Israel), OCJ and ICMS (USA), Director R\&D of INRC Polymate (Israel) and Nanotech Industries, Inc. (USA); Chairman of the UNESCO chair «Green Chemistry»; President of Israel Association of Inventors; Laureate of the Golden Angel Prize, Polymate INRC; P.O.Box 73, Migdal Ha’Emeq, Israel, 10550, e-mail: figovsky@gmail.com

\title{
THE NEW TECHNOLOGY FOR MANUFACTURING POLYMER NANOPOWDER. PART I.
}

\section{Extended Abstract:}

The authors studied the problem of pollution by waste polymers. The research is dedicated to the methods of recycling of polymers, in particular PTFE. It was shown that the most environmentally friendly disposal methods with the lowest cost are the methods based on stepwise mechanical dispersion. Technologies and devices based on the principles of abrasive vortex dispersion polymers have been developed and tested. To protect the intellectual property of the author the staff of LLC TARK (Ukraine) and the Science and Technology Center Polymate (Israel) registered patent USA «Method and apparatus for manufacturing submicron polymer powder» No. 12 / 981.202 of 29.12.2010.

Key words: polymers, waste, polytetrafluoroethylene, recycling, environmental friendliness, abrasive grinding, aerodynamic dispersion, rotary-vortex machine.

DOI: dx.doi.org/10.15828/2075-8545-2015-7-5-20-45

MaChine-REAdable information ON CC-LiCENSES (HTML-CODE) IN METADATA OF THE PAPER

$<$ a rel=»license» href=»http://creativecommons.org/licenses/by/4.0/»><img alt=»Лицензия Creative Commons» style=»border-width:0» src=»https://i.creativecommons.org/l/by/4.0/88x31.png» $/></$ a $><$ br $/>$ Произведение «<span xmlns:dct=»http://purl.org/dc/terms/» href=»http://purl.org/dc/dcmitype/Text»property=»dct:title» rel=»dct:type»>The new technology for manufacturing polymer nanopowder. Part I.</span>» созданное автором по имени <a xmlns:cc=»http: // creativecommons.org/ns\#» href=»Nanotehnologii v stroitel'stve = Nanotechnologies in Construction. 2015, Vol. 7, no. 5, pp. 20-45. DOI: dx.doi.org/10.15828/2075-8545- 2015-7-5-20-45.» property=»cc:attributionName» rel=»cc:attributionURL»> Gryaznov I.V., Figovsky O.L. </a>, публикуется на условиях < a rel=»license» href=»http://creativecommons.org/licenses/ by/4.0/»>лицензии Creative Commons «Attribution» («Атрибуция») 4.0 Всемирная </a $>$. $<$ br $/>$ Основано на произведении с <a xmlns:dct=»http://purl.org/dc/terms/» href=» http://nanobuild.ru/en_EN/nanobuild-5-2015/» rel=»dct:source»> http:// nanobuild.ru/en_EN/nanobuild-5-2015/</a $>$. $<$ br / > Разрешения, выходящие за рамки данной лицензии, могут быть доступны на странице <a xmlns:cc=»http://creativecommons.org/ns\#»href=»figovsky@gmail.com» rel=»cc:morePermissions» $>$ figovsky@gmail.com $</ \mathrm{a}>$. 


\section{References:}

1. Europe in figures. Eurostat Annual. 2006 - 2007. 371 p.

2. Suprunenko O. Musornaja jera ot rassveta do zakata. [Garbage era from dawn to sunset]. Jekologija i Obshhestvo [Ecology and Society]. 2006. № 4. (In Russian).

3. The island of trash in the Pacific Ocean has already exceeded twice the territory of the United States. Information Digest «noospherogenesis» (On the way to sustainable development of mankind) № 3, 2008. Category: Environment.

4. Chegodaev D.D., Naumov Z.K., Dunaevskaya Y.S. Ftoroplasty [Fluorines]. Leningrad. Goskhimizdat. 1971. 192 p. (In Russian).

5. Bouznik V.M. Ftorpolimery: sostojanie otechestvennoj himii ftorpolimerov, perspektivy razvitija [Fluoropolymers: state of domestic fluoropolymers chemistry, development prospects]. Russian Chemical Journal (magazine Rus. Chem. of the Society named after D.I .Society Mendeleev). 2008. V. LII, № 3. (In Russian).

6. Borschev V.J. Oborudovanie dlja pererabotki sypuchih materialov [Equipment for processing of bulk materials]. Tutorial. Moscow. Mashinostroenie-1. 2006. 208 p. (In Russian).

7. Pugachev A.K., Roslyakov O.A. Pererabotka ftoroplastov v izdelija: Tehnologija i oborudovanie [Processing of fluoropolymers in the product: technology and equipment] Saint-Petrsburg. Himija [Chemistry], 1987. 168 p. (In Russian).

8. Gorbatsevich G.N. et al. Materialy na osnove modificirovannogo politetraftorjetilena [Materials based on modified PTFE]. Materialy, oborudovanie i resursosberegajushhie tehnologii: materialy mezhdunar. nauch.-tehn. konf. [Materials, equipment and resource-saving technologies: Proceedings of the International Scientific and Engineering Conference] Mogilev. Bel. Ros. University Press, 2008. Part 2. P. 29-30. (In Russian).

9. Villemson A.L. Sovremennoe sostojanie i perspektivy mirovogo rynka ftorpolimerov [Current state and prospects of the world market of fluoropolymers]. Mezhdunarodnye novosti mira plastmass [International news in the world of plastics]. 2008. № 11-12. P. 20-23. (In Russian).

10. Struck V.A. et al. Optimizacionnaja tehnologija funkcional'nyh kompozicionnyh materialov na osnove politetraftorjetilena [Optimization technology of functional composite materials based on PTFE]. Promyshlennost' regiona: problemy i perspektivy innovacionnogo razvitija [Regional Industry: Problems and perspectives of innovation development]. Monograph. Grodno GGAU, 2008. P. 302-315. (In Russian).

11. Gorbatsevich G.N. et al. Germetizirujushhie kompozity na osnove politetraftorjetilena s povyshennoj iznosostojkost'ju [Sealants composites based on PTFE with improved wear jresistance]. Kompozicionnye materialy v promyshlennosti: materialy XXVIII mezhdunar.konf [Composite Materials Industry: Proc. of the XXVIII 
international. conf.]. Kiev. UIC «Nauka. Tehnika. Tehnologija» [Educational and publishing center «Science. Equipment. Technology»]. 2008. P. 64-70. (In Russian).

12. Struck V.A. et al. Metodologija formirovanija funkcional'nyh nanomaterialov na osnove politetraftorjetilena [Methodology of formation of functional nanomaterials based on PTFE]. Effektivnost' realizacii nauchnogo, resursnogo i promyshlennogo potenciala v sovremennyh uslovijah: materialy VIII mezhdunar. promyshl. konf. [Efficiency of research, resource and industrial potential in modern conditions: materials of the VIII Intern. indus. Conf.]. Kiev. UIC «Science. Equipment. Technology» [Educational and publishing center «Science. Equipment. Technology»]. 2008. P. 48-54. (In Russian).

13. Kuryavy V.G., Tsvetnikov A.K., Gorbunov A.V. Morfologicheskoe stroenie produktov piroliza ul'tradispersnogo politetraftorjetilena [The morphological structure of the pyrolysis products of ultrafine PTFE ]. Perspektivnye materialy [Perspective materials] 2002. № 6. P. 72-74. (In Russian).

14. Bouznik V.M., Tsvetnikov A.K. Ul'tradispersnyj politetraftorjetilen kak osnova dlja novyh perspektivnyh materialov [Ultrafine PTFE as a base for new promising materials]. Vestnik DVO RAN [Bulletin FEB RAS]. 1993. № 3. P. 39. (In Russian).

15. Sedlis L.V. Telomery tetraftorjetilena. [Telomeres tetrafluoroethylene]. Moscow: NIITEKHIM. 1974. 45 p. (In Russian).

16. Charlesby A. The Decomposition of Polytetrafluoroethylene by Pile Radiation / Charlesby. Great Britain Atomic Energy Reserch Establishment AERE M / R. 1952. $296 \mathrm{p}$.

17. Currie J.A., Pathmanand N. Anal. Calorim., 3 (1974) 629.

18. Popova G.S., Budtov V.P., Ryabikova V.M. et al. Analiz polimerizacionnyh plastmass [Analysis of polymer plastics]. Leningrad. Himija [Chemistry], 1988. (In Russian).

19. Korbakova A.I., Makulova I.D., Marchenko E.N. et al. Toksikologija ftororganicheskih soedinenij i gigiena truda $\mathrm{v}$ ih proizvodstve [Toxicology organofluorine compounds and occupational hygiene for the production of them]. Moscow. Medicina [Medicine], 1975.

20. Blagodarnaia O.A. Gigiena truda v sovremennyh proizvodstvah po pererabotke ftoroplasta-4 [Occupational health in modern production processing fluoroplastic-4]. Gigiena truda v himicheskoj i himiko-farmacevticheskoj promyshlennosti [Occupational hygiene in the chemical and pharmaceutical industries]. NF Izmerova. Moscow. 1976. p. 115-123. (In Russian).

21. Shadrina N.E., Kleshcheva M.S., Loginova N.N. et al. Analiz karbocepnyh ftoropolimerov metodom piroliticheskoj gazovoj hromatografii [Analysis of the carbonchain fluoropolymers by pyrolysis gas chromatography]. Zhurnal analiticheskoj himii [Journal of Analytical Chemistry]. 36, 6 (1981) 1125.

22. Morisaki S. Thermochim. acta. 25, 2 (1978) 171. 
23. Madorskiy C. Termicheskoe razlozhenie organicheskih polimerov [The thermal decomposition of organic polymers]. Moscow. Mir. 1967. P. 328.

24. Degteva T.G., Sedov I.M., Khamidov J.A., Kuz'minskii A.S. Okislenie ftorsoderzhashhih polimerov [Oxidation of fluoropolymers]. Dep. Uzb. Chemical Journal. Tashkent, 1971. № 3699 .

25. Ftorpolimery / ed. L.A. Walla. Moscow. Mir. 1975. 448 p.

26. Mashkov J.K. Tribofizika i svojstva napolnennogo ftoroplasta [Tribophysics and properties of filled fluoroplastic] Omsk. Publishing House of the Omsk State Technical University, 1997. 250 p. RU 2528054.

27. Uminsky A.A., Tsvetnikov A.K., Ippolitov E.G., Pogodaev V.P., Kedrinskii I.A., Sobolev G.L., Borovnev L.M. Sposob poluchenija poliftorugleroda [A method for preparing polyfluorocarbon] Patent. A s. 1662100 RF MKI 5 C08G 113/18.

28. Tsvetnikov A.K., Uminsky A.A., Tsarev V.A. Ustanovka dlja pererabotki politetraftorjetilena [Plant for the reprocessing of polytetrafluoroethylene]. Patent. 1763210 RF MKI V29V 17/00 /. 4 p.

29. Tsvetnikov A.K. Plant for the reprocessing of polytetrafluoroethylene: Patent. 2035308 RF MKI V29V 17/00 /. 4c., Il. P. 1763210 RF MKI V29V 17/00.

30. Bouznik V.M., Tsvetnikov A.K., Matveenko L.A. Dispergirovanie politetraftorjetilena dlja racional'nogo ispol'zovanija materiala [The dispersion of PTFE for the rational use of material]. Himija v interesah ustojchivogo razvitija [Chemistry for sustainable development]. 1996. № 4. P. 489.

31. Tsvetnikov A.K., Bouznik V.M., Matvienko L.A. Sposob poluchenija tonkodispersnogo PTFJe i soderzhashhaja ego masljanaja kompozicija [A method for producing fine particle PTFE and oil composition containing it] Patent. 2100376 RF MKI 6 C08F 114/26, C08J 11/04, 11/10.

32. Filatov V.Y., Fuchs S.L., Sukhanov E.N., Kazienkov S.A., Hitrin S.V. Sposob pererabotki ftoroplastov i materialov, ih soderzhashhih, s polucheniem ul'tradispersnogo ftoroplasta i perftorparafinov [Method for processing fluoropolymers, and materials containing them to produce ultrafine fluoroplastic and perftorparafinov]. RU 2528054. Vyatka State University (RU).

33. Arsenyev S.L., Lozovitsky I.B.,. Sirik Y.P, Turaev V.V., Odnoral M.V., Danilov E.A. Tehnicheskoe predlozhenie: Tehnologija i oborudovanie dispergirovanija vtorichnogo politetraftorjetilena [Technical Proposal: The technology and equipment of the secondary dispersion of polytetrafluoroethylene]. Pavlograd, 2004. UDC 678.743.41 / 45: 678.06 621,921: 620.178.16.

34. Dubinskaya A.M. Prevrashhenija organicheskih veshhestv pod dejstviem mehanicheskih naprjazhenij [The transformations of organic substances under the influence of mechanical stresses]. Uspehi himii [Russian Chemical Reviews]. 1999. 68 (8). P. 708-724.

35. Azgaldov G.G., Reichman E.P. O kvalimetrii [About qualimetry]. Moscow. Ed. Standards, 1973. 220 p. 
36. Alekseev V.P., Azarov A.I., Drozdov A.F., Krotov P.E. Novaja vihrevaja tehnika dlja sredstv ohrany truda [New Whirlpool appliances for labor protection funds]. Vihrevoj jeffekt i ego primenenie v tehnike: Materialy 4-j Vsesojuznoj nauchnotehnicheskoj konferencii [Vortex effect and its applications in engineering: Proceedings of the 4th All-Union Scientific and Technical Conference]. Kuybyshev. Kuai. 1984. P. 104-111.

37. Babakin B.S., Vygodin V.A. Bytovye holodil'niki i morozil'niki: Spravochnik [Household refrigerators and freezers: A Handbook]. Moscow. Kolos. 2000. P. 455-456.

38. Biryuk V.V. Vihrevoj jeffekt jenergeticheskogo razdelenija gazov v aviacionnoj tehnike i tehnologii [Vortex effect of energy separation of gases in aeronautical engineering and technology]. Izvestia Vuzov. Aviacionnaja tehnika [Aviation equipment]. 1993, № 2, p. 20-23.

39. Kiryuhin D.P., Kim I.P., BouznikV.M., Ignatieff L.N., Kuryavyi V.G., Sakharov S.G. Radiacionno-himicheskij sintez telomerov tetraftorjetilena i ih ispol'zovanie dlja sozdanija tonkih zashhitnyh ftorpolimernyh pokrytij [Radiation-chemical synthesis of telomeres of tetrafluoroethylene and use them to create a thin protective coating fluoropolymer]. Russian Chemical Journal (magazine Rus. Chem. of the Society named after D.I .Society Mendeleev). 2008, V. LII, № 3.

40. Gryaznov I., Gryaznov S., Gryaznova A., Figovsky O. Method and apparatus for manufacturing submicron polymer powder. Patent No. 12/981.202 of 29.12.2010.

The Part II of the paper of Gryaznov I.V. and Figovsky O.L. "The New Technology for Manufacturing Polymer Nanopowder" will be published in the issue 6/2015 of the journal "Nanotechnologies in Construction".

\section{DeAr COlleagues!}

THE REFERENCE TO THIS PAPER HAS THE FOLLOWING CITATION FORMAT:

Gryaznov I.V., Figovsky O.L. The new technology for manufacturing polymer nanopowder. Part I. Nanotehnologii v stroitel'stve $=$ Nanotechnologies in Construction. 2015, Vol. 7, no. 5, pp. 20-45. DOI: dx.doi.org/10.15828/2075-85452015-7-5-20-45. (In Russian).

\section{Contact information}

Figovsky Oleg Lvovich

figovsky@gmail.com 
УДК 69.001.5

Автор: ГРЯЗНОВ Игорь Васильевич, инженер, директор НТП ООО ТАРК; ул. Новая, 3а, 43, г. Павлоград, Днепропетровская обл., Украина, 51413, e-mail: lustann@mail.ru;

Автор: ФИГОВСКИЙ Олег Львович, действительный член Европейской академии наук, иностранный член РИА и РAACH, главный редактор журналов SITA, OCJ и RPCS, директор компании «Nanotech Industries, Inc.», Калифорния, США, директор Международного нанотехнологического исследовательского центра «Polymate» (Израиль), зав. кафедрой ЮНЕСКО «Зелёная химия», президент Израильской Ассоциации Изобретателей, Лауреат Golden Angel Prize, Polymate INRC; P.O.Box 73, Migdal Ha’Emeq, Израиль, 23100, e-mail: figovsky@gmail.com

\section{НОВАЯ ТЕХНОЛОГИЯ ИЗГОТОВЛЕНИЯ ПОЛИМЕРНЫХ НАНОПОРОШКОВ. ЧАСТЬ I.}

\section{АННОТАЦИЯ К СТАТЬЕ (АВТОРСКОЕ РЕЗЮМЕ, РЕФЕРАТ):}

Изучена проблема загрязнения окружающей среды отходами полимеров. Исследованы методы утилизации полимеров, в частности, ПТФЭ. Отмечено, наиболее экологически чистыми и минимально затратными методами утилизации являются методы, основанные на постадийном механическом диспергировании. Разработаны и экспериментально апробированы технология и устройство, основанные на принципах абразивно-вихревого диспергирования полимеров. С целью защиты интеллектуальной собственности авторами - сотрудниками предприятия ООО ТАРК (Украина) и научно-технического центра Polymate (Израиль) был зарегистрирован патент CIIA «Method and apparatus for manufacturing submicron polymer powder» // Патент 12/981,202 от 29.12.2010.

Ключевые слова: полимеры, отходы, политетрафторэтилен, утилизация, экологическая чистота, абразивное измельчение, аэродинамическое диспергирование, роторно-вихревой агрегат.

DOI: dx.doi.org/10.15828/2075-8545-2015-7-5-20-45 
МАШИНОЧИТАЕМАЯ ИНФОРМАЦИЯ О СС-ЛИЦЕНЗИИ В МЕТАДАННЫХ СТАТЬИ (HTML-КОд):

$<\mathrm{a}$ rel=»license» href=»http://creativecommons.org/licenses/by/4.0/»><img alt=»Лицензия Creative Commons» style=»border-width:0» src=»https://i.creativecommons.org/l/by/4.0/88x31.png» $/></$ a $><$ br $/>$ Произведение «<span xmlns:dct=»http://purl.org/dc/terms/» href=»http://purl.org/dc/dcmitype/Text»property=»dct:title»

$\mathrm{rel}=» d c t: t y p e »>$ Новая технология изготовления полимерных нанопорошков. Часть I. $</$ span $>$ » созданное автором по имени <a xmlns:cc=»http://creativecommons.org/ns\#» href=»Нанотехнологии в строительстве. - 2015. - Том 7, № 5. - C. $20-45$. - DOI: dx.doi.org/10.15828/2075-8545-2015-7-5-20-45.» property=»cc:attributionName» rel=»cc:attributionURL»>Грязнов И.В., Фиговский О.Л.</a>, публикуется на условиях <a rel=»license» href=» http://creativecommons.org/licenses/ by/4.0/»>лицензии Creative Commons «Attribution» («Атрибуция») 4.0 Всемирная </a > <br />Основано на произведении с <a xmlns:dct=»http://purl.org/dc/terms/»href=»http://nanobuild.ru/ru_RU/nanobuild-5-2015/»rel=»dct:source»>http:// nanobuild.ru/ru_RU/nanobuild-5-2015/</a $>$. $<$ br $/>$ Разрешения, выходящие за рамки данной лицензии, могут быть доступны на странице <a xmlns:cc=»http://creativecommons.org/ns\#» href=»figovsky@gmail.com»rel=»cc:morePermissions» $>$ figovsky@gmail.com $</ \mathrm{a}>$.

\section{Глобальные проблемы}

Последние 60 лет являются временем активного создания и совершенствования промышленных технологий производства новых синтетических полимерных материалов, необратимо вошедших во все области жизни человека и человеческого общества. Однако большинство вновь созданных синтетических материалов, обладающих ценными качествами, с точки зрения экологов имеют существенный недостаток высокую стойкость к воздействию природных факторов, обуславливающую длительное вредоносное присутствие их отходов в природе.

По происхождению отходы полимеров классифицируются следующим образом:

- производственно-технологические отходы;

- отходы производственного использования;

- отходы общественного потребления.

В среднем каждый человек в мире за день образует около 1 кг бытовых отходов. Сегодня на одного жителя ежедневно приходится: в Cоединенных Штатах около 2 кг мусора, в Бельгии, Великобритании, Германии, Японии на одного человека ежегодно приходится 460-600 кг бытовых отходов, в Австрии и Финляндии - свыше 600 кг [1].

Из 200 кг отходов, ежегодно генерируемых каждым человеком, $10-15 \%$ составляют отходы полимеров. $К$ сожалению, этот показатель неуклонно возрастает. Каждый год в мире производится около 100 млн тонн полимерных изделий, из которых 10\% в виде отходов неизбежно попадают в мировой океан. Экспертами Программы окружающей среды ООН в 2006 году определен объём плавающего полимерного

http://nanobuild.ru 


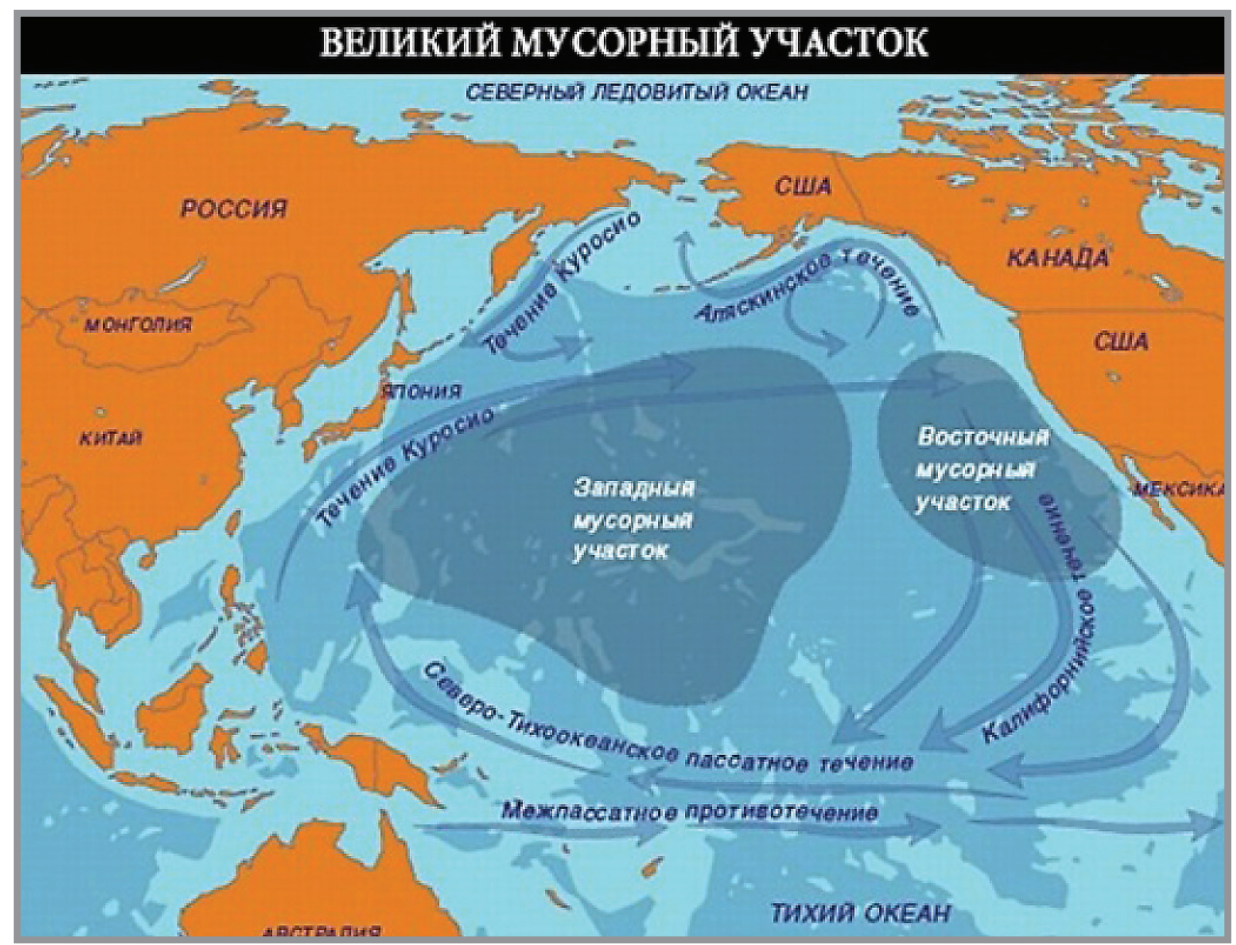

Pис. 1. Остров из мусора в Тихом океане

мусора в количестве до 46 тысяч предметов, на квадратную милю морской поверхности $[2,3]$. Устойчивость полимерных отходов к агрессивным средам, их гигантское количество и длительное время деструкции в природе обусловили загрязнение окружающей среды, вылившееся в глобальную экологическую проблему. По указанной причине человек должен прийти на помощь природе, оградить её от губительного воздействия химических продуктов, обеспечивая экологическую чистоту как технологических и производственных процессов, так и процессов использования и утилизации отходов вновь созданных синтетических материалов. Необходима разработка и применение эффективных экологически чистых способов утилизации отходов полимеров. Тем не менее, человечество по-прежнему идёт по самому простому пути - пути накопления полимерных отходов, оставляя эту проблему последующим поколениям. В нынешней практике, минимизируя техногенное загрязнение окружающей среды, человек применяет следующие методы:

- термические способы переработки отходов полимеров (пиролиз отходов полимеров с получением жидких или газообразных продуктов и сжигание с образованием газов и золы); 
- $\quad$ накопление отходов полимеров на полигонах и захоронение в могильниках с отравлением тем самым почвы.

Очевидно, что традиционные подходы к проблеме утилизации полимерных отходов неизбежно приводят к загрязнению окружающей среды. Наиболее проблемными в этом плане являются отходы политетрафторэтилена (ПТФЭ), накапливающиеся в окружающей природе и достигающие, в связи со сложностью утилизации, 40\% от объема его производства [4, 5, 6, 7]. По данным компании The Freedonia Group Inc., мировой рынок фторполимеров стабильно растет (рис. 2).

Лидирующее место по производству фторполимеров занимают США, на втором месте - Западная Европа, третье место принадлежит Китаю; с 2000 года мировое потребление фторполимеров растет на 5-6\% ежегодно в машиностроительной, электротехнической, нефтедобывающей и других сферах промышленности [8,9]. Именно по причине высокой востребованности ПТФЭ в высокотехнологичных отраслях важно совершенствование процессов производства и использования фторполимеров, а также создание эффективных технологий рециклинга и возврата ПТФЭ в эксплуатацию на основе современных научных исследова-

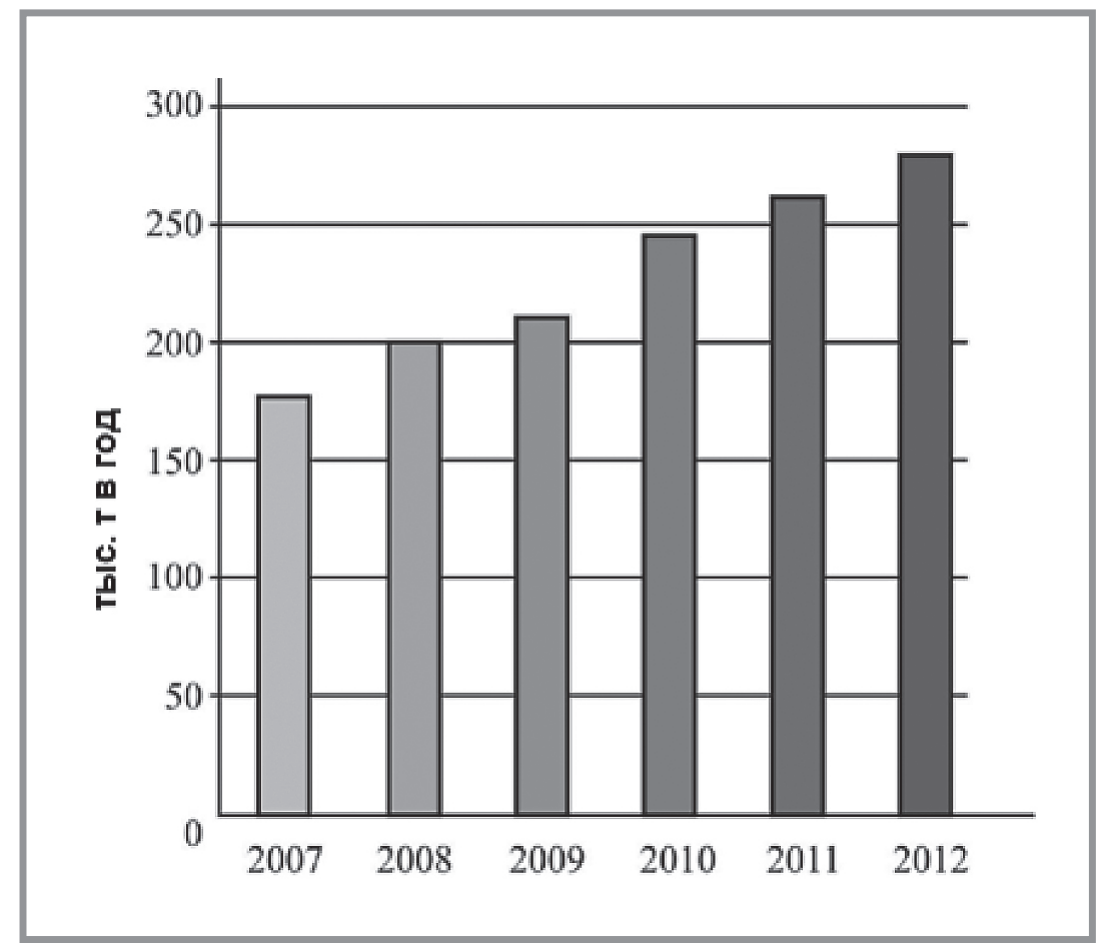

Рис. 2. Мировой рынок фторполимеров 
ний [10]. Мировое производство и потребление ПТФЭ в количественном отношении ниже, чем у доминирующей на мировом рынке четверки полимеров (ПЭ, ПП, ПС, ПВХ), но в своей нише его применение считается наиболее эффективным и даже безальтернативным. Для переработки отходов ПТФЭ весьма актуальны подходы, связанные с размерными эффектами, используемыми в нанотехнологиях и обеспечивающими создание принципиально новых научно-технических решений и методов. Учитывая высокую стабильность ПТФЭ, целесообразно переводить отходы ПТФЭ из макросостояния в удобные для применения в дальнейшей переработке микро- и ультрадисперсное состояния, в которых этот материал также может быть применён в составе композиционных материалов различного назначения.

Актуальность проблемы утилизации отходов полимеров в целом и ПТФЭ в частности ставит мировому научно-техническому сообществу задачу создания высокопродуктивных безотходных технологий, обеспечивающих стабильную, экономичную и экологически чистую переработку отходов ПТФЭ.

\section{ПТФ3 и методы переработки}

Для наиболее полного понимания сущности проведенных работ приводим немного информации о том, что представляет собой ПТФЭ.

Политетрафторэтилен является высокомолекулярным соединением. Макромолекула ПТФЭ состоит из большого числа групп $\mathrm{CF}_{2}$, соединенных химическими связями. Полимеризацию мономера (ТФЭ) осуществляют различными методами. Наиболее распространенным является метод полимеризации ТФЭ в водной среде в присутствии инициаторов: персульфитов аммония, натрия или калия при давлении 5,0 МПа. Данный процесс является экзотермическим и характеризуется выделением теплоты - 25 ккал на 1 моль $\mathrm{CF}_{2}=\mathrm{CF}_{2}$. Продукт полимеризации представляет собой рыхлый, волокнистый, легко комкующийся порошок белого цвета [6].

Макромолекула ПТФЭ представляет собой цилиндрическую спираль, внешняя оболочка которой сформирована атомами фтора. Спиральная форма макромолекулы обусловлена тем, что имеющий большой радиус атом фтора из-за стерических затруднений не укладывается в интервал 0,254 нм, соответствующий промежутку между 
двумя атомами углерода основной цепи. Каждая связь $\mathrm{C}-\mathrm{C}$ при повороте от плоскости, обусловленном наличием двух присоединённых атомов фтора, приблизительно на $17^{\circ}$ увеличивает это расстояние до 0,27 нм, что коррелирует к двум радиусам атома фтора. Этим же обусловлены уникальная химическая стойкость, полное отсутствии адгезии, низкое трение и высокая пластичность при низких температуpax. Уникальной особенностью ПТФЭ является то, что при его нагреве выше температуры плавления кристаллитов $\left(600^{\circ} \kappa\right)$ не происходит его переход из высокоэластического состояния в вязкотекучее, как это характерно для других термопластов. При постепенном охлаждении от температуры плавления или несколько более высокой происходит кристаллизация ПТФЭ.

ПТФЭ является наиболее термостойким из термопластов, механизмы его термической деструкции хорошо изучены и описаны в [11]. В вакууме при температуре $773^{\circ} \kappa$ и более макромолекула ПТФЭ деструктирует с выделением тетрафторэтилена. В интервале температур $473-678^{\circ} \mathrm{K}$ количество выделяющихся газообразных продуктов очень мало, и их не удается полностью идентифицировать. При температуре выше $698^{\circ} \mathrm{K}$ скорость разложения ПТФЭ существенно повышается. Уникальная химическая стойкость ПТФЭ объясняется высокой прочностью связи $\mathrm{C}-\mathrm{F}$ и недоступностью связи $\mathrm{C}-\mathrm{C}$ для действия химических реагентов вследствие её плотного экранирования спирально расположенными атомами фтора. Строение молекулы определяют низкий уровень сил межмолекулярных связей и адгезионного взаимодействия ПТФЭ с другими материалами. Особые физико-химические свойства ПТФЭ позволяют эксплуатировать изделия из него в агрессивных средах в температурном диапазоне от 4 до $533^{\circ} \kappa$, при этом верхний предел температуры эксплуатации определяется сохранением параметров характеристик физико-механических свойств. Фторопластовые изделия характеризуются высокими диэлектрическими и триботехническими характеристиками (коэффициент трения $<0,05)$. Значение коэффициента трения на уровне $0,04 \ldots 0,05$ действительно при трении образцов по углеродистой стали без смазки при скорости скольжения до $1-10^{-2} \mathrm{M} / \mathrm{c}$. Увеличение температуры вызывает снижение коэффициента трения ПТФЭ, что выгодно отличает данный материал от других полимеров, у которых при повышении температуры коэффициент трения без смазки, как правило, увеличивается [12]. 
Все вышеуказанные качества обуславливают то, что производство микропорошков ПТФЭ в виде различных торговых марок в США, Японии и Западной Европе исчисляется тысячами тонн. Например, компания DuPont выпускает ультрадисперсный порошок ПТФЭ под фирменными наименованиями Zonyl, Fluoroadditive 1100 и TEFLON MP, DuPont Krytox (CШA) - гранулированные порошки Teflon PTFE, Lubrizol Corporation (CШA) - дисперсии FLUOTRON, Western Reserve Chemical corporation (CШA) - порошок PTFE Plastolon P-550, Shamrock Technologies Inc (СШA) - порошки ряда Fluoro PTFE Micronized (средний размер частиц 1-2 микрона), коллоидные дисперсии ряда NanoFLON PTFE, микропорошки ПТФЭ «Форум» и «Томфлон» (компании ООО «Форум» и ООО НПФ «Томфлон» (РФ), компания Daikin - под именем Polyflon L-5, компания Ausimont - микропорошок Polymist F5, фирма Dyneon производит Hostaflon TF, компания Imperial Chemical Industry - Fluon FL, компания ICI (CША) производит коммерчески доступный продукт, известный как FLUOROGLIDE FL 1700, компания Solvay Solexis Inc (Italy) производит PTFE марки Algoflon, компания «Dongyue Polymer Material Co.Ltd» (Китай)- порошок ПТФЭ марок MSII, WZ-II, MS-III, WZ-III, MS-IV, WZ-IV, MS-V, WZ-V.

Как уже упоминалось, наиболее удобным состоянием ПТФЭ для переработки является мелкодисперсный порошок. Известные способы получения порошкообразного ПТФЭ различной степени дисперсности в зависимости от технологии подразделяются на синтетические, механические, радиационные, лазерные, термические, термогазодинамические $[13,14]$.

Сущность синтетических способов состоит в синтезе из тетрафторэтилена суспензионным или эмульсионным методами суспензий и органогелей ПТФЭ с размерами частиц 3-5 мкм [15]. Способы достаточно производительны и используются в промышленной практике, однако сложны в технологическом отношении, требуют реагентов высокой чистоты, обуславливающих высокую стоимость получаемого продукта. Кроме того, затруднено получение частиц более мелкого размера. Выделение частиц из суспензий в сухом виде приводит к их агломерированию. Естественно, данный способ не может применяться для переработки вторичного ПТФЭ с целью получения микродисперсного порошка.

Механические способы основаны на механическом измельчении крупных образцов ПТФЭ с помощью специальных мельниц или при со- 
ударении частиц в сверхзвуковых газовых потоках. Этот способ измельчения эффективен для хрупких материалов, таких, каким ПТФЭ становится при температуре ниже жидкого азота. Размеры частиц порошка, получаемого названным способом, имеют большой разброс и находятся в диапазоне 5-100 мкм; регулирование размера частиц и получение монофракционного продукта затруднено. Исследованиями установлено, что одного лишь механического размола исходного сырья недостаточно для достижения необходимой степени микродисперсности. Например, порошок Microflon, производимый предприятием MikroTechnik GmbH (ФРГ). Характеристики фракционного состава порошка Microflon, получаемого при размоле, подтверждают изложенное выше.

таблища 1

Распределение размера частиц Mikroflon

\begin{tabular}{|c|c|}
\hline Ряд в $\boldsymbol{\mu \mathbf { m }}$ & доля \\
\hline $0-10$ & $1,6 \%$ \\
\hline $10-13$ & $2,3 \%$ \\
\hline $13-18$ & $3,7 \%$ \\
\hline $18-24$ & $5,6 \%$ \\
\hline $24-32$ & $10,3 \%$ \\
\hline $32-44$ & $26,1 \%$ \\
\hline $44-60$ & $33,2 \%$ \\
\hline $60-81$ & $14,3 \%$ \\
\hline $81-110$ & $2,1 \%$ \\
\hline $110-150$ & $1,0 \%$ \\
\hline $150-200$ & $0,01 \%$ \\
\hline
\end{tabular}

График фракционного распределения частиц Mikroflon (cм. рис. 3) показывает, что большая доля полученных частиц входит в размерный диапазон между 30 и $60 \mu \mathrm{m}$.

Радиационный способ получения дисперсных частиц основан на низкой устойчивости ПТФЭ к ионизирующим излучениям. Деструкция массивных образцов ПТФЭ происходит вследствие разрыва макромолекул под действием потока частиц или $\gamma$-квантов [16]. Облучение образцов ПТФЭ приводит к уменьшению молекулярного веса продукта в 10-30 раз и обеспечивает получение порошкообразных частиц порошка с размером до 5 мкм. 


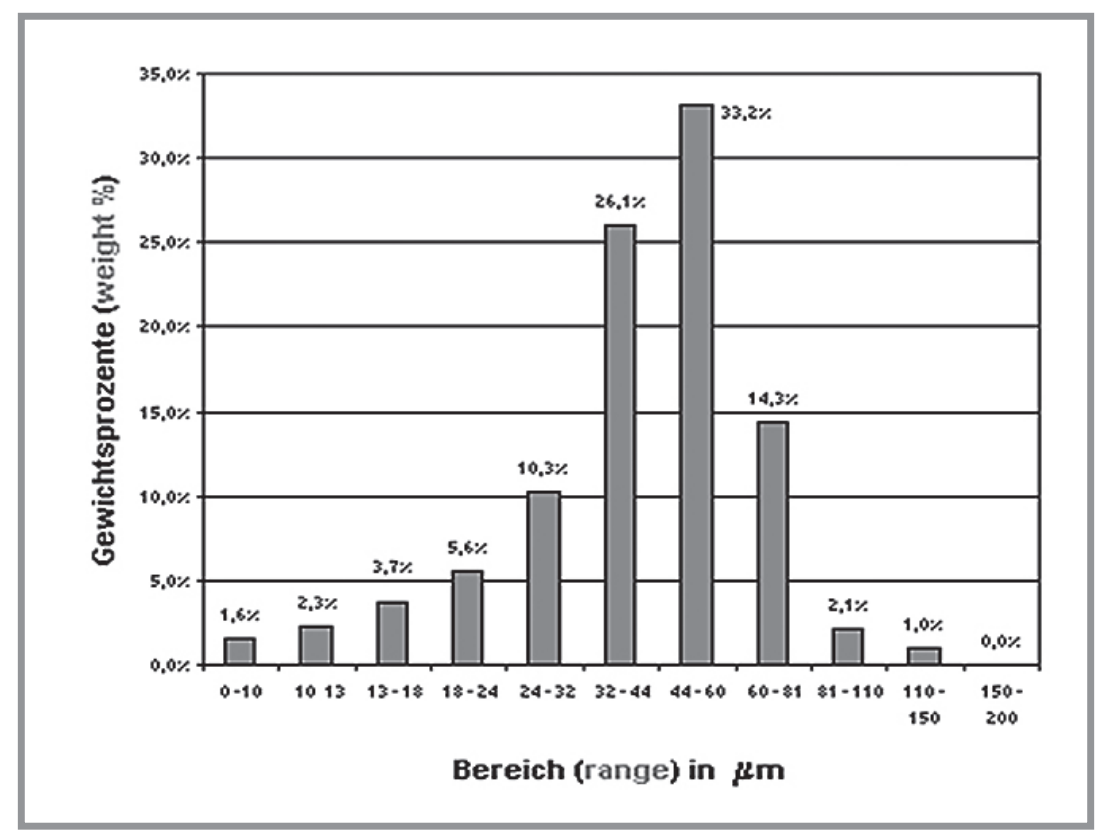

Puc. 3. Фракционирование частиц Mikroflon

Радиационная технология получения дисперсных частиц является общепринятой в мире и, по мнению ООО «Фторполимерные технологии», наиболее эффективной в коммерческом плане. Упомянутая компания разработала электронно-лучевую технологию производства ультрадисперсного ПТФЭ и пластичных смазок на его основе и в 2004 году произвела первую опытно-промышленную партию порошка ПТФЭ, который был зарегистрирован под торговой маркой TOMFLON ${ }^{\text {TM }}$. В отличие от стандартного ПТФЭ, производимого в России, микронный размер частиц порошка ТОМФЛОН делает возможным его широкое применение в сферах, непосредственно не связанных с традиционным использованием фторполимеров. Применяемый в виде добавки микропорошок TOMFLON ${ }^{\mathrm{TM}}$ обладает весьма ценным качеством сообщать свои свойства модифицируемой субстанции. Его применение эффективно в части снижения трения, повышения износостойкости, повышения коррозионной стойкости, увеличения термостойкости.

Лазерные способы предполагают локальную деструкцию массивного образца ПТФЭ под действием лазерного облучения. В работе оценивается принципиальная возможность существования способа. Возможность его широкого применения проблематична по причинам низкой производительности и высокой стоимости [15]. 
Политетрафторэтилен (ПТФЭ) - самый термостойкий из всех гомополимеров. Термическая деструкция ПТФЭ изучена и обобщена в работе [17]. Политетрафторэтилен при пиролизе распадается на тетрафторэтилен (ТФЭ ), выход которого составляет 90\%, гексафторпропилен (ГФП) и октафторциклобутан [18]. В воздушной среде основными продуктами термоокислительной деструкции ПТФЭ являются ТФЭ, ГФП, перфторизобутилен, $\mathrm{HF}, \mathrm{CO}, \mathrm{CO}_{2}$ [19-23]. Состав продуктов, полученных при разложении ПТФЭ в атмосфере различных газов, изучен в работе [24]. Существует мнение, что термические способы диспергирования основаны на реполимеризации мономера (газообразного тетрафторэтилена (ТФЭ) или других продуктов разложения ПТФЭ, образующихся в процессе термодеструкции). Однако этот процесс возможен только при избыточном давлении ТФЭ и наличии условий полимеризации. Выход конечного продукта в указанных способах чрезвычайно низок, что исключает их практическое использование для производства порошкообразного ПТФЭ в необходимых масштабах.

В Институте химии Дальневосточного отделения Российской академии наук (Владивосток) совместно с Институтом катализа Сибирского отделения Российской академии наук (Новосибирск) кандидатом химических наук А.Е. Цветниковым и сотрудниками разработан термогазодинамический (ТГД) метод, который частично решает отмеченные выше проблемы и может обеспечить промышленное производство ультрадисперсного политетрафторэтилена (УПТФЭ), регулируемого по качеству. Разработанная технология отличается от известных, т.к. базируется на новых подходах к механизму термодеструкции ПТФЭ.

Общепринятым считается утверждение, что при нагреве блочный ПТФЭ разлагается на мономеры тетрафторэтилена $\left(\mathrm{C}_{2} \mathrm{~F}_{4}\right)$ в газовой фазе $[23,25]$. Количество образующегося мономера зависит от температуры. Ниже $678^{\circ} \mathrm{K}$ оно незначительно, а выше $773^{\circ} \mathrm{K}$ наблюдается разложение исходного ПТФЭ и образование газовой фазы. Механизм разложения двухстадийный. Первая стадия заключается в индуцировании свободного радикала, вторая - в отщеплении мономера от свободнорадикального конца полимерной цепи.

Поскольку неспаренный электрон остается в полимерной цепи, то очевидна возможность многих повторений стадии отщепления мономера. Инициирование процесса деструкции макромолекул ПТФЭ проис- 


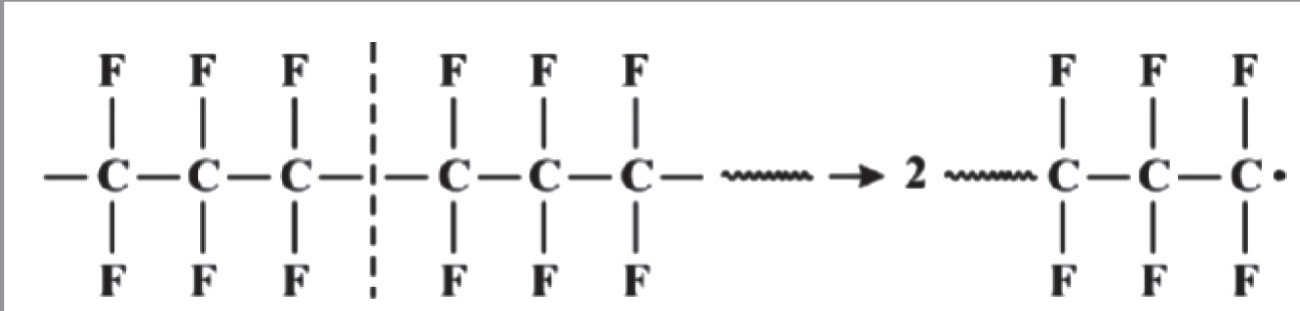

Рис. 4. Индуцирование свободного радикала

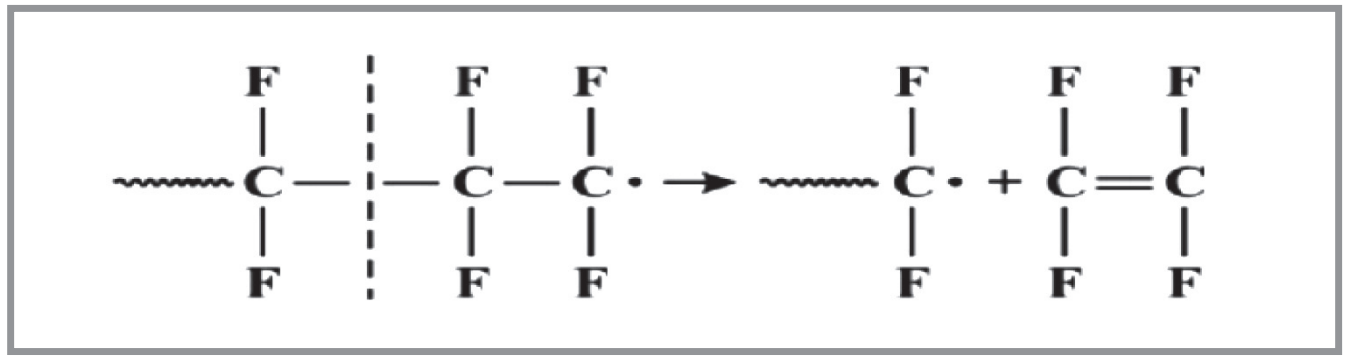

Рис. 5. Отщепление мономера от свободного радикала

ходит за счет термического разрыва более слабых углерод-углеродных связей $(-\mathrm{C}-\mathrm{C}-)$ на напряженных участках полимерной цепи,таковыми могут быть, например, участки изгиба. С повышением температуры разрушаются и обычные связи углеродной цепи (-C-C-). Обычно предполагают, что термодеструкция полимерной цепи происходит внутри блока с выделением лишь газообразных мономеров, а процесс в этом случае зависит от формы и размеров исходного материала, состава и давления окружающей газовой среды [26]. Установлено, что реальный процесс термодеструкции блочного ПТФЭ является более сложным, что подтверждается экспериментальными и теоретическими исследованиями [27-31].

Получаемые указанным способом порошки ПТФЭ представляют собой смесь различных фракций с размером частиц от 0,15 до 1 мкм и более. Экспериментальные данные подтверждают невозможность получения пиролитическим методом однородного по фракционному составу и молекулярной структуре микродисперсного порошка ПТФЭ. В настоящее время технология производства ультрадисперсного ПТФЭ термогазодинамическим методом (ТГД), а также продуктов на его основе защищена рядом патентов Российской Федерации и товарных знаков 
[27-32]. Проведены комплексные исследования состава и строения продуктов ТГД-синтеза - ультрадисперсного политетрафторэтилена (УПТФЭ) (торговая марка продукта «Форум»).

Пиролитическое разложение ПТФЭ с последующей конденсацией продуктов разложения согласно ТГД-методу обеспечивает получение ультрадисперсного порошка ПТФЭ, содержащего продукты рекомбинации и неполного разложения ПТФЭ, но с малым выходом (25-30\% от массы сырья). При этом остальное сырье переходит в газообразную фазу, а получаемый порошок ПТФЭ представляют собой смесь различных фракций с размером частиц от 0,15 до 1 мкм и более. По указанным причинам, а также в связи с высокой энергоёмкостью и недопустимым загрязнением атмосферы газообразными фторсодержащими продуктами, производство микродисперсного порошка ПТФЭ в промышленных масштабах ТГД-методом нецелесообразно.

Все вышеперечисленные способы имеют ограничения для получения качественного дисперсного продукта на основе ПТФЭ. Для улучшения качества порошка ПТФЭ используют совокупность способов. Например, дополнительная механическая обработка порошка, полученного радиационным способом, позволяет уменьшить размеры частиц до 1-3 мкм.

С целью разработки высокопродуктивного и экологически чистого метода получения микродисперсного порошка ПТФЭ сотрудниками предприятия ООО «ТАРК» были проведены исследовательские и экспериментальные работы в следующих направлениях:

- исследование методов диспергирования ПТФЭ в ультра- и микродисперсные порошки, обеспечивающие продуктивный рециклинг вторичного ПТФЭ;

- создание научно обоснованных методов получения ультра- и микродисперсных порошков ПТФЭ и оборудования для их реализации.

\section{Абразивное измельчение}

В ряду механических методов измельчения ПТФЭ практически неисследованным является процесс абразивного измельчения. С целью проверки возможности применения абразивного измельчения для получения мелкодисперсного ПТФЭ и определения оптимальных параметров названного процесса предприятием ООО «ТАРК» были проведены 
исследования процесса абразивного измельчения ПТФЭ с использованием абразивного инструмента различной геометрической формы, содержащего рабочий слой из абразивных зерен, скрепленных между собой связкой. $K$ абразивным инструментам относятся шлифовальные круги, шлифовальные головки, бруски, сегменты, абразивные ленты.

Как известно, молекулярная масса ПТФЭ находится в диапазоне 140 000-500 000 у.е. Длина связи -C-C- в углеродной цепи ПТФЭ равна 0,27 нм. Соответственно, длина макромолекулы может быть от 3787 до 13450 нм. Молекулярные цепочки указанной длины могут быть достаточно успешно разрушены механическими методами при условии минимизации влияния окружающих макромолекул ПТФЭ. Это становится возможным при разрушении кристаллитов ПТФЭ путём воздействия микроскопических режущих элементов, например, кристаллов. Известно также, что алмаз кристаллизуется в кубической системе, отвечающей самой плотной упаковке атомов и содержащей всего 18 атомов углерода. Именно прочная связь атомов углерода объясняет высокую твёрдость алмаза. В кристаллической решётке алмаза каждый атом связан с четырьмя соседними атомами, расположенными в вершинах правильного тетраэдра. Расстояние между соседними атомами C-C равно 0,27 нм. Постоянный размер кристаллической решетки ал-

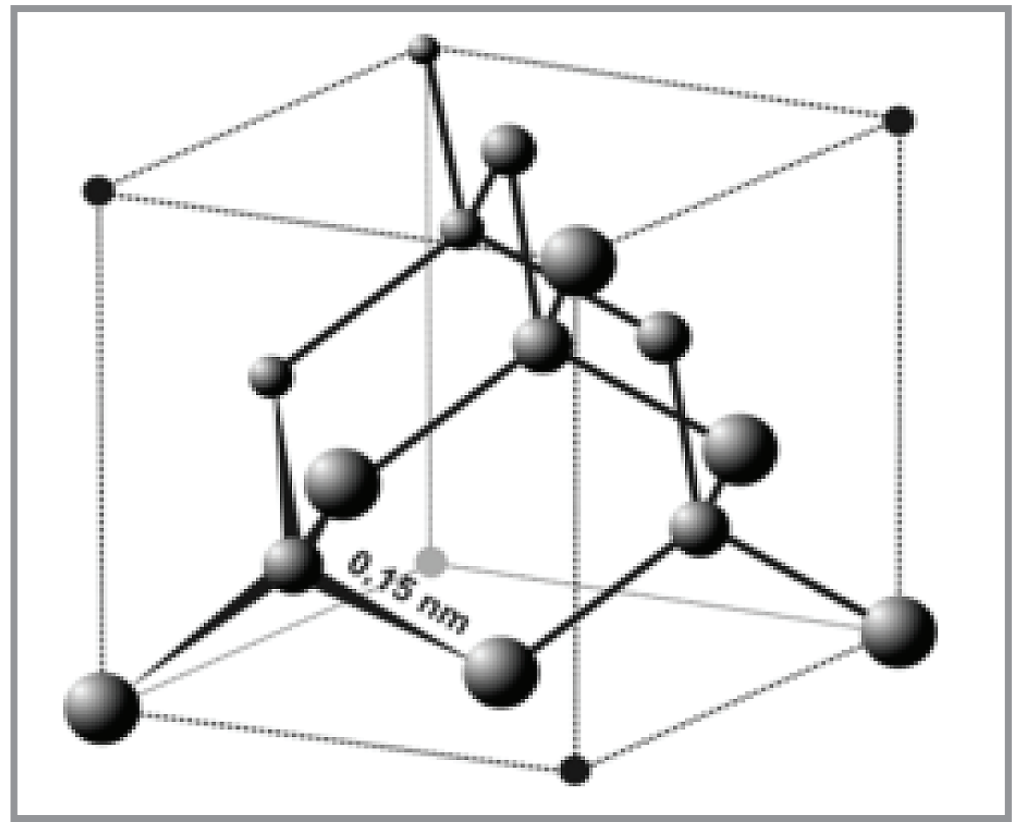

Рис. 6. Кристаллическая решетка алмаза 
маза - 0,356 нм. Сопоставляя размеры режущих кристаллов алмаза и макромолекул ПТФЭ, мы видим, что абразивное измельчение ПТФЭ происходит на макромолекулярном уровне, что вполне приемлемо для дальнейшего получения субмикронных частиц ПТФЭ. Данное предположение было проверено экспериментально.

\section{Абразивное измельчение с помощью ручного абразивного инструмента}

В начале исследований было проведено измельчение блока ПТФЭ вручную с помощью плоского стального и плоского алмазного надфилей. Улавливание полученных частиц осуществлялось с помощью кюветы, наполненной дистиллированной водой. Частицы ПТФЭ были изучены под микроскопом и сфотографированы. Во всех экспериментах в качестве масштабного элемента использовался волос толщиной 50 мкм.

В процессе проведения работ с помощью ручного абразивного инструмента установлено следующее:

- абразивное измельчение как начальная стадия технологического процесса диспергирования вторичного ПТФЭ достаточно продуктивно;

- абразивное измельчение с использованием ручного инструмента в виде стального и алмазного надфилей при различных скоростях обработки в диапазоне 0.05-0.6м/сек обеспечивает получение преимущественно крупных частиц ПТФЭ в виде стружки;

- $\quad$ алмазный инструмент обеспечивает наиболее высокую производительность процесса измельчения ПТФЭ.

\section{Абразивное измельчение с помощью машинного абразивного инструмента}

Для измельчения бруска ПТФЭ использовался заточной станок, на котором устанавливались:

1. резиноалмазный круг;

2. обдирочный крупнозернистый круг диаметром 125 мм;

3. отрезной крупнозернистый круг диаметром 230 мм;

4. специально изготовленный стальной круг диаметром 145 мм и толщиной 13 мм с нанесенным на цилиндрическую поверхность алмазным порошком на медно-никелевой связке. 
Проведенные эксперименты с помощью заточного станка при одинаковой частоте вращения шпинделя дали следующие результаты:

1. обработка бруска ПТФЭ резиноалмазным кругом проводилась с линейной скоростью 20 м/сек: в процессе обработки данный абразив засаливается фторопластом, что существенно снижает производительность процесса измельчения; алмазные частицы выпадают из абразивного круга;

2. обработка бруска ПТФЭ с использованием обдирочного крупнозернистого круга диаметром 125 мм с линейной скоростью обработки 18 м/сек: обнаружено значительное засаливание поверхности абразива и существенный нагрев обрабатываемого фторопластового блока; производительность процесса измельчения низкая;

3. обработка бруска ПТФ с использованием отрезного крупнозернистого круга диаметром 230 мм с линейной скоростью обработки 32 м/сек: износа инструмента не обнаружено; засаливание рабочей поверхности круга незначительное; нагрев фторопластового образца отсутствует; производительность процесса измельчения существенно выше, чем в предыдущих опытах, и составила примерно $0.03 \mathrm{mм} /$ сек; количество летучих частиц достигло примерно $20 \%$ от общей производительности;

4. обработка бруска ПТФ с использованием специально изготовленного стального круга диаметром 145 мм и толщиной 13 мм с нанесенным на цилиндрическую поверхность алмазным порошком на медно-никелевой связке: измельченный продукт, получаемый при абразивном диспергировании алмазной поверхностью, представляет собой преимущественно частицы в виде стружки с поперечником $10 . . .30$ мкм и длиной до 200 мкм.

Производительность процесса абразивного диспергирования определена по результатам проведенных опытов. Приблизительно за 2 сек брусок сечением $1 \mathrm{~cm}^{2}$ изнашивали кругом алмазной поверхностью толщиной 13 мм на глубину $1 \mathrm{mм}$, что составляет $0,0125 \mathrm{~cm}^{3} /$ сек или 0,02625 г $/$ сек $=94,5$ г час.

Результаты экспериментальной оценки показали, что увеличение линейной скорости абразива от $0,1 \ldots 0,5$ до 20 м/сек приводит к уменьшению размера частиц, созданию наиболее оптимальной формы и повышению производительности процесса абразивного измельчения. Более того, увеличение линейной скорости абразива до 24 м/сек способству- 
ет дальнейшему измельчению частиц. По мере повышения линейной скорости абразива от 24 до 32 м/сек количество легколетучих микродисперсных частиц возрастает до $20 \%$ от общего количества переработанного материала.

При этом были подтверждены:

- возможность получения микрочастиц из блочного ПТФЭ путем его абразивной обработки;

- достижение максимальной производительности процесса при условии применения алмазного абразивного инструмента;

- факт того, что основным параметром, определяющим размер частиц ПТФЭ, является линейная скорость режущей поверхности абразивного инструмента;

- эффективная величина линейной скорости режущей поверхности 30-40 м/сек и более.

Измельченный продукт, получаемый при абразивном диспергировании, представляет собой преимущественно частицы в виде стружки с поперечником 10...30 мкм и длиной до 200 мкм и их агломераты. Такая дисперсность вполне пригодна для переработки в формовые изделия. Однако для приготовления тонких суспензий лакокрасочных материалов, насыщения пористых деталей для подшипников скольжения, модификации смазочных материалов необходимо получать частицы ПТФЭ субмикронной дисперсности, имеющие компактную форму, близкую к сферической. Для этой цели в технологической цепи предусмотрена дальнейшая переработка частиц в аэромеханическом дезинтеграторе [33].

Основываясь на вышеизложенном, была сформирована концепция разрабатываемой технологии и принято решение о создании экспериментальной диспергирующей установки для отработки технологии диспергирования.

\section{Теоретические предпосылки}

Целью, на достижение которой были направлены усилия исследователей, являлось создание энергоэффективной высокопроизводительной технологии, обеспечивающей наиболее полную переработку отходов блочного ПТФЭ в ультрадисперсный порошок. С этой целью были разработаны способ и оборудование для его осуществления. 
Концептуально разрабатываемая технология представляет собой последовательность процессов, включающую:

- абразивное истирание блочного ПТФЭ;

- подачу и удаление несущей газовой среды;

- формирование потоков частиц в объёме несущей газовой среды;

- $\quad$ разгон, соударение и вихревое аэродинамическое диспергирование волокнистых частиц ПТФЭ, полученных в результате абразивного истирания;

- оптимизацию формы и классификацию диспергированных частиц ПТФЭ за счёт одновременного воздействия на них центробежных и центростремительных сил, пульсирующих аэродинамических сил во встречных турбулентных потоках, чередующихся сжатии и разрежении газовой среды, а также воздействия знакопеременного температурного поля.

Реализация разработанного способа осуществляется в специально спроектированном роторно-вихревом агрегате (РВА), обеспечивающем:

- изменение физико-механических свойств перерабатываемого ПТФЭ за счёт уменьшения его молекулярного веса в результате абразивного измельчения;

- получение волокнистых частиц ПТФЭ и их агломератов своими размерами приближающихся к размерам частиц теломеров тетрафторэтилена;

- аэродинамический нагрев волокнистых частиц ПТФЭ в несущей газовой среде;

- генерирование пульсирующих аэродинамических сил во встречных турбулентных потоках;

- вихревое аэромеханическое диспергирование нагретых волокнистых частиц ПТФЭ;

- снижение поляризации в частицах ПТФЭ, за счёт термостимулирования релаксации внутримолекулярных напряжений;

- оптимизацию формы частиц ПТФЭ воздействием знакопеременных механических и температурных нагрузок;

- $\quad$ разделение получаемых ультрадисперсных частиц ПТФЭ по массе и удаление получаемых ультрадисперсных частиц ПТФЭ при одновременном воздействии на них центробежных и центростремительных сил. 
Необходимым условием для одновременного протекания перечисленных процессов является абразивное истирание блочного ПТФЭ и интенсивное высокочастотное механическое нагружение, приводящее к разрыву макромолекул и измельчению ПТФЭ в результате абразивного и вихревого аэродинамического воздействий в едином объёме.

Несмотря на то, что ПТФЭ является в целом неполярным полимером, на его поверхности и в приповерхностном объеме существуют дипольные участки молекул, создающие стабильные во времени электретные свойства.

Характерным для любого диэлектрика процессом, возникающим при воздействии на него механического напряжения, является поляризация - ограниченное смещение связанных зарядов или ориентация дипольных молекул, обуславливающая слипание полученных частиц ПТФЭ. Электрет с «замороженной» поляризацией является термодинамически неравновесным объектом. Его состояние неустойчиво, а нагревание ведет к быстрому необратимому разрушению поляризации диэлектрика. Неравновесность - основное свойство электретного состояния, каковы бы ни были конкретные механизмы его получения.

Релаксация - переход в равновесное неполяризованное, незаряженное состояние - характерна для любого электрета. Релаксация электретного состояния сопровождается уменьшением величины избыточного заряда, накопленного электретом, поверхностного потенциала и др. явлениями. Она может происходить как при постоянной температуре (изотермическая релаксация - ИТР), так и при повышении температуры со временем по определенному закону (термостимулированная релаксация - ТСР). Релаксация также ускоряется под воздействием механических напряжений, деформаций, ионизирующих излучений, атмосферной влажности, пыли и др. Стимулирование релаксации внутримолекулярных напряжений, соответствующее снижение поляризации в частицах ПТФЭ и переход частиц в равновесное неполяризованное, незаряженное состояние при воздействии знакопеременных механических и температурных нагрузок способствуют оптимизации формы получаемых ультрадисперсных частиц и, соответственно, получению сыпучего порошка ПТФЭ.

Часть ІІ статьи Грязнова И.В., Фиговского О.Л. "Новая технология изготовления полимерных нанопорошков" будет опубликована в нолере 6/2015 журнала "Нанотехнологии в строительстве".

http://nanobuild.ru 


\section{У ВАЖАЕМЫЕ КОЛЛЕГИ!}

ПРИ ИСПОЛЬЗОВАНИИ МАТЕРИАЛА ДАННОЙ СТАТЬИ

ПРОСИМ ДЕЛАТЬ БИБЛИОГРАФИЧЕСКУЮ ССЫЛКУ НА НЕЁ:

Грязнов И.В., Фиговский О.Л. Новая технология изготовления полимерных нанопорошков. Часть I. // Нанотехнологии в строительстве. - 2015. - Том 7, № 5. - C. 20-45. - DOI: dx.doi.org/10.15828/2075-8545-2015-7-5-20-45.

\section{DeAR Colleagues!}

THE REFERENCE TO THIS PAPER HAS THE FOLLOWING CITATION FORMAT:

Gryaznov I.V., Figovsky O.L. The new technology for manufacturing polymer nanopowder. Part I. Nanotehnologii v stroitel'stve $=$ Nanotechnologies in Construction. 2015, Vol. 7, no. 5, pp. 20-45. DOI: dx.doi.org/10.15828/2075-85452015-7-5-20-45. (In Russian).

\section{Библиографический список:}

1. Европа в цифрах. - Річник Євростата. - 2006 - 2007. - 371 с.

2. Супруненко О. Мусорная эра от рассвета до заката // Экология и Общество. 2006.- № 4 .

3. Остров из мусора в Тихом океане уже превысил в два раза территорию США // Информационный дайджест «Ноосферогенез»(на пути к устойчивому развитию человечества). - 2008 г. - № 3, рубрика «Экология» .

4. Чегодаев Д.Д., Наумова З.К., Дунаевская Я.С. Фторопласты. - Л.: Госхимиздат, 1971. - $192 \mathrm{c}$.

5. Бузник B.M. Фторполимеры: состояние отечественной химии фторполимеров, перспективы развития // Российский химический журнал (журнал Рос. хим. обва им. Д.И. Менделеева). - 2008. - Т. LII, № 3.

6. Борщев B.Я. Оборудование для переработки сыпучих материалов: учеб. пособие. М.: Издательство «Машиностроение-1», 2006. - 208 с.

7. Пугачев А.К. Переработка фторопластов в изделия: Технология и оборудование / А.К. Пугачев, О.А. Росляков. - Л.: Химия, 1987. - 168 с.

8. Материалы на основе модифицированного политетрафторэтилена / Г.Н. Горбацевич и др. // Материалы, оборудование и ресурсосберегающие технологии: материалы междунар. науч.-техн. конф. - Могилев: Бел.-Рос. ун-т, 2008. - Ч. 2. C. $29-30$.

9. Виллелсон А.Л. Современное состояние и перспективы мирового рынка фторполимеров // Международные новости мира пластмасс. - 2008. - № 11-12. - С. 20-23. 
10. Оптимизационная технология функциональных композиционных материалов на основе политетрафторэтилена / В.А. Струк и др. // Промышленность региона: проблемы и перспективы инновационного развития: монография. - Гродно: ГГАУ, 2008. - С. 302-315.

11. Герметизирующие композиты на основе политетрафторэтилена с повышенной износостойкостью / Г.Н. Горбацевич и др. // Композиционные материалы в промышленности: материалы XXVIII междунар.конф. - Киев: УИЦ «Наука. Техника. Технология», 2008. - С. 64-70.

12. Струк B.A. и др. Методология формирования функциональных наноматериалов на основе политетрафторэтилена // Эффективность реализации научного, ресурсного и промышленного потенциала в современных условиях: материалы VIII междунар. промышл. конф. - Киев:УИЦ «Наука. Техника. Технология», 2008. - С. 48-54.

13. Курявый В.Г. Морфологическое строение продуктов пиролиза ультрадисперсного политетрафторэтилена / В.Г. Курявый, А.К. Цветников, А.В. Горбунов, В.М. Бузник // Перспективные материалы. - 2002. - № 6. - С. 72-74.

14. Бузник B.M. Ультрадисперсный политетрафторэтилен как основа для новых перспективных материалов / В.М. Бузник, А.К. Цветников //Вестник ДВО РАН. 1993. - № 3. - С. 39.

15. Седлис Л.В. Теломеры тетрафторэтилена. - Москва: НИИТЭХИМ, 1974. - 45 с.

16. Charlesby A. The Decompozition of Polytetrafl uoroethylene by Pile Radiation / Charlesby // Great Britain Atomic Energy Reserch Establishment AERE M/R. 1952. $-296 \mathrm{p}$.

17. Currie J.A., Pathmanand N. Anal. Calorim., 3 (1974) 629.

18. Попова Г.С., Будтов В.П., Рябикова В.М. и др. Анализ полимеризационных пластмасс. - Ленинград: Химия, 1988.

19. Корбакова А.И., Макулова И.Д., Марченко Е.Н. и др. Токсикология фторорганических соединений и гигиена труда в их производстве. - Москва: Медицина, 1975.

20. Благодарная O.A. Гигиена труда в современных производствах по переработке фторопласта-4 // Гигиена труда в химической и химико-фармацевтической промышленности / Н. Ф. Измерова. - Москва, 1976. - С. 115-123.

21. Шадрина Н.Е., Клещева М.С., Логинова Н.Н. и др. Анализ карбоцепных фторополимеров методом пиролитической газовой хроматографии // Журнал аналитической химии. $-36,6-1981$. -1125.

22. Morisaki S. Thermochim. acta.-25, 2-1978-171.

23. Мадорский С. Термическое разложение органических полимеров. - Москва: Мир, 1967. - C. 328.

24. Дегтева Т.Г., Седова И.М., Халидов Х.А., Кузьлинский А.С. Окисление фторсодержащих полимеров // Деп . в Узб . хим . журн. - Ташкент, 1971. - № 3699-71.

25. Фторполимеры / под ред. Л.А. Уолла. - М.: Мир, 1975. - 448 с.

26. Машков Ю.К. Трибофизика и свойства наполненного фторопласта / Ю.К. Машков. - Омск: Изд-во ОмГТУ, 1997. - 250 с. - RU 2528054.

27. Улинский А.А., Цветников А.К., Ипполитов Е.Г., Погодаев В.П., Кедринский И.А., Соболев Г.Л., Боровнев Л.М. Способ получения полифторуглерода / А. с. 1662100 РФ, МКИ 5 С08G 113/18 . 
28. Цветников А.К., Улинский А.А., Царев В.А. Установка для переработки политетрафторэтилена: П. 1763210 РФ, МКИ В29В 17/00. - 4 с.

29. Цветников А.К. Установка для переработки политетрафторэтилена: П. 2035308 РФ, МКИ В29В 17/00 /. 4с., - П. 1763210 РФ, МКИ В29В 17/00.

30. Бузник B.M. Диспергирование политетрафторэтилена для рационального использования материала / В.М. Бузник, А.К. Цветников, Л.А. Матвеенко // Химия в интересах устойчивого развития. - 1996. - № 4. - С. 489.

31. Цветников А.К., Бузник В.М., Матвеенко Л.А. Способ получения тонкодисперсного ПТФЭ и содержащая его масляная композиция / П. 2100376 РФ, МКИ 6 С08F 114/26, C08J 11/04, 11/10.

32. Филатов В.Ю., Фукс С.Л., Суханова Е.Н., Казиенков С. А., Хитрин С.В. Способ переработки фторопластов и материалов, их содержащих, с получением ультрадисперсного фторопласта и перфторпарафинов // Вятский государственный университет (ФГБОУ ВПО «ВятГУ»). - RU 2528054.

33. Арсеньев С.Л., Лозовицкий И.Б., Сирик Ю.П., Тураев В.В., Однорал М.В., Данилов E.A. Техническое предложение: Технология и оборудование диспергирования вторичного политетрафторэтилена. - Павлоград, 2004. - УДК: 678.743.41/45:678.06 621.921:620.178.16.

34. Дубинская А.М. Превращения органических веществ под действием механических напряжений // Успехи химии. - 1999. - 68 (8). - С. 708-724.

35. Азгальдов Г.Г., Райхлан Э.П. О квалиметрии. - М. Изд. стандартов, 1973. - 220 с.

36. Алексеев В.П., Азаров А.И., Дроздов А.Ф., Кротов П.Е. Новая вихревая техника для средств охраны труда // Вихревой эффект и его применение в технике: Материалы 4-й Всесоюзной научно-технической конференции. - Куйбышев: КуАИ, 1984. C. 104-111.

37. Бабакин Б.С., Выгодин В.А. Бытовые холодильники и морозильники: Справочник. - М.: Колос, 2000. - С. 455-456.

38. Бирюк В.В. Вихревой эффект энергетического разделения газов в авиационной технике и технологии // Изв. Вузов. Авиационная техника. - 1993, № 2. - С. 20-23.

39. Кирюхин Д.П., Ким И.П., Бузник В.М., Игнатьева Л.Н., Курявый В.Г., Сахаров С.Г. Радиационно-химический синтез теломеров тетрафторэтилена и их использование для создания тонких защитных фторполимерных покрытий // Рос. хим. журнал. (журнал Рос. хим. об-ва им. Д.И. Менделеева). - 2008. - T. LII, № 3.

40. Gryaznov I., Gryaznov S., Gryaznov A., Figovsky O. Method and apparatus for manufacturing submicron polymer powder // Патент 12/981,202 от 29.12.2010.

Контакты

Фиговский Олег Львович figovsky@gmail.com 